\title{
Does experience influence judgments of pain behaviour? Evidence from relatives of pain patients and therapists
}

Kenneth M Prkachin $\mathrm{PhD}^{1}$, Patty Solomon $\mathrm{PhD}^{2}$, Teresa Hwang $\mathrm{BA}^{2}$, Susan R Mercer $\mathrm{PhD}^{3}$

KM Prkachin, P Solomon, T Hwang, SR Mercer.

Does experience influence judgments of pain behaviour?

Evidence from relatives of pain patients and therapists.

Pain Res Manage 2001;6(2):105-112.

OBJECTIVE: Judgments about an individual's pain can be profoundly important to sufferers. Relatively few studies have examined variables that may affect observers' judgments of the pain of others. The present article reports two studies investigating the relationship between different kinds of exposure to pain problems and observers' ratings of the pain intensity of patients.

DESIGN: In the first study, 82 observers were classified into groups with positive and negative family histories of chronic pain. They viewed a videotape showing the facial expressions of shoulder pain patients undergoing physiotherapy assessments and rated the pain experienced by the subjects. In the second study, the data from observers having no experience with pain problems were compared with data collected from therapists having considerable experience with pain problems.

RESULTS: Observers with a positive family history of chronic pain attributed greater pain to the patients than those with a negative family history of chronic pain. Professionals' pain judgments were lower than those of control subjects.

CONCLUSIONS: Together, the findings imply that one's experiences with the different problems of pain patients may affect pain judgments. Alternative interpretations of the findings are considered.

Key Words: Bias; Experience; Facial expression; Observation; Pain, Sensitivity; Shoulder pain

\section{L'expérience modifie-t-elle les jugements portés sur les comportements révélateurs de la douleur? Réponse de parents ayant connu des personnes souffrantes ainsi que de thérapeutes}

OBJECTIF : Les jugements sur la douleur peuvent s'avérer extrêmement importants pour les personnes souffrantes. Relativement peu d'études ont examiné les variables susceptibles de modifier le jugement d'observateurs porté sur la douleur des autres. Le présent article fait état de deux études sur le lien entre les différents problèmes concernant l'exposition à la douleur et l'évaluation de l'intensité de la douleur par des observateurs dans un groupe de patients.

PLAN D'ÉTUDE : Dans la première étude, 82 observateurs ont été classés en deux groupes : ceux ayant une expérience familiale positive de la douleur chronique et ceux ayant une expérience négative. On leur a présenté, sur bande vidéo, l'expression faciale de patients éprouvant des douleurs à l'épaule au cours d'une évaluation en physiothérapie et on leur a demandé de coter la douleur ressentie par les sujets. Dans la deuxième étude, les chercheurs ont comparé les données provenant d'observateurs qui n'avaient pas été exposés à la douleur à celles provenant de physiothérapeutes qui y avaient été fortement exposés.

RÉSULTATS : Les observateurs qui avaient des antécédents familiaux positifs de douleur chronique ont accordé une cote plus élevée que ceux qui avaient des antécédents familiaux négatifs. L'évaluation de la douleur par les professionnels était plus faible que celle des témoins.

CONCLUSION : Dans l'ensemble, les résultats donnent à penser que l'expérience personnelle de la douleur peut modifier le jugement sur la douleur. Sont également envisagées d'autres interprétations possibles des résultats.

${ }^{1}$ University of Northern British Columbia, Prince George, British Columbia; ${ }^{2}$ McMaster University, Hamilton, Ontario; ${ }^{3}$ University of Otago,

Dunedin, New Zealand

Correspondence: Dr KM Prkachin, Psychology Program, University of Northern British Columbia, 3333 University Way, Prince George,

British Columbia V2N 4Z9. Telephone 250-960-6633, fax 250-960-5536, e-mail kmprk@unbc.ca

Received for publication March 28, 2000. Accepted October 10, 2000 
$\mathrm{T}$ he actions that people take in the presence of a sufferer are profoundly important. This is true both in the natural environment and in the clinic. In the natural setting, an observer's perception of a sufferer's pain may determine whether he or she will encourage the sufferer to seek help, rest, relax or move on to other activities. According to Fordyce (1), such consequences may strengthen or weaken the sufferer's future pain behaviour. In clinical settings, a therapist's judgment of the presence or intensity of a sufferer's pain may make the difference between aggressive or conservative treatments and may govern the pace of rehabilitation efforts.

The variables that affect judgments about the pain of others are poorly understood. To investigate these problems, it is helpful to understand pain as a communication process in which some antecedent event (eg, tissue damage, ongoing injury, central stimulation) induces an internal state. The sufferer's behaviour then changes in a way that provides an external referent (eg, linguistic and paralinguistic cues, grimacing, self-protective or self-care behaviour) for that state. This referent may then be 'broadcast' into the social environment where observers can detect, interpret and take action on it. Rosenthal (2) has outlined an A (internal state) to B (behavioural sign) to C (observer's decoding) model of this process and has discussed the nature of the questions that can be addressed at each point.

Some research on pain behaviour has focused on the A to $\mathrm{B}$ phase of this process: investigators have attempted to identify behaviours that encode the internal state. For example, a set of facial actions that take place during pain has been identified (3). These actions appear to provide a sensitive indication of the intensity of pain, when evaluated against the criterion of the sufferer's judgment (4-7). Relatively fewer studies have focused on the $\mathrm{B}$ to $\mathrm{C}$ phase of this process how people decode the evidence about pain available in behaviour - and when they have, it has been primarily to validate the properties of the pain signal itself. There has been little inquiry into the possibility that observers may show systematic differences in how they detect, interpret and take action on evidence of pain in others.

Prkachin et al (6) provided evidence that observers' judgments of others' pain may pose special problems that warrant attention. Untrained observers viewed videotapes of shoulder pain patients who had undergone a series of movements during a physiotherapy assessment. The patients had provided ratings ('A' in Rosenthal's model) of their pain with each movement. Measurement of their facial behaviour during the movement provided an index of the external referent (B) to their pain. The observers gave their judgments $(\mathrm{C})$ of the intensity of the pain the patients felt on each trial, using the same rating scale used by the patients. The observers' judgments were highly reliable and sensitive to gross variations in patients' pain states. Nevertheless, several aspects of their performance were problematic. First, they did not appear to be especially sensitive to fine variations in patients' facial expressions. Second, the correlations between their judgments and the patients' subjective reports were not as strong as those between measured facial behaviour and the patients' reports. This suggested that although the evidence that observers could use to make a reliable judgment about patients' pain was present, they did not use it effectively. Third, observers underrated the absolute magnitude of the patients' pain (relative to the criterion of the patients' selfreports) systematically and appreciably.

These findings suggest that untrained observers may have a less than optimal ability to use information about suffering that is available in the behavioural display. Further understanding of judgment processes may enhance our ability to identify when this is likely to be a special problem and may suggest means of remedying the problem. In addition, these findings draw attention to a distinction that can be made between two aspects of performance in such situations. On the one hand, observers may vary in their sensitivity to variations in a sufferer's pain. This is indicated by covariations between the magnitude of the observer's judgment and either the behavioural referent or the patient's report. On the other hand, observers may vary in the weight they place on a particular bit of evidence about pain. That is, observers may systematically underrate (or, conceivably, overrate) pain relative to sufferers, independent of their sensitivity to variations in the sufferers' states.

It is reasonable to ask what variables may affect observers' evaluations of the pain of others. One natural expectation is that experience should influence how observers process information about pain behaviour and thereby affect their ratings of others' pain. Two groups of people that may be expected to show systematic variations in their judgments of pain are people who have lived with a chronic pain sufferer and health care professionals who deal with pain sufferers on a routine basis. The present paper presents two studies in which the pain ratings of such individuals were contrasted with those of people having little experience with pain problems and with those of sufferers themselves.

\section{STUDY 1}

Surprisingly, few studies have examined how family members interpret pain behaviour, although there has been no lack of speculation about the role of family members in the development and treatment of pain problems $(8,9)$. Family systems theorists $(10,11)$ suggest that family characteristics such as overinvolvement and enmeshment may contribute to pain problems, but they are silent on whether pain patients' family members perceive pain behaviour in any unique way. Similarly, the behavioural approach to chronic pain (1) emphasizes that family members are sensitive to the expression of pain and may respond to maintain or minimize it. However, it has little to say about how family members process information about pain in their afflicted relatives. Moreover, the processes emphasized by both behavioural and family systems theorists are based on clinical observations of patients referred for specialized treatment, and may therefore be unrepresentative of those that affect pain sufferers and their families in general. 
The purpose of the first study was to examine whether experience living with an individual who suffers from persistent pain might be related to evaluations of pain expressions. Pain expressions of a group of pain patients were rated by observers who had or had not lived with someone with a pain problem. Because existing theories are silent on the question of how family members of pain sufferers perceive pain expressions, no a priori predictions could be made. Logic suggests two incompatible expectations. On the one hand, people who have lived with a pain sufferer would have had greater opportunity to observe pain expressions and relate them to other indications of suffering than people with little experience with pain sufferers. Consequently, they may be expected to show greater sensitivity to pain expressions. On the other hand, experience as a member of a family of someone with a pain problem might inure the individual to evidence of suffering as a result of adaptation (12). If so, they would be expected to show lesser sensitivity.

\section{Patients and methods}

Observers were 82 undergraduate students (17 males, 65 females) enrolled in Introductory Psychology classes at McMaster University, Hamilton, Ontario. They participated for course credit. The observers were recruited to take part in a study on factors affecting the judgments of pain expressions. On volunteering for the study, observers were provided with a description of chronic pain that emphasized persistence beyond the time required for healing and lasting for at least six months. Observers were then asked to indicate whether they had or had not lived with a family member who met the criteria for having chronic pain. Observers were asked to interpret 'having lived with' as within the past five years and having been in the presence of the individual for significant amounts of time. On reporting for the testing session, group membership was reaffirmed by having observers complete a questionnaire indicating the site of the pain problem affecting their family member, the specific family member involved, the duration (six months to more than five years) and frequency of pain episodes (one to two times per month to two to three times per day), and their usual intensity (not at all intense to extremely intense).

\section{Apparatus and materials}

A 25 min videotape was specially constructed for the purposes of this study. The excerpts were taken from a previous study of the facial reactions of shoulder pain patients to a series of challenges to their affected shoulder conducted during a physiotherapy assessment (7). The patients had been videotaped while they were exposed to 10 range of motion tests. At the end of each test they rated the intensity of the pain they experienced using the ratio scales of pain intensity and affect developed by Heft et al (13). Please note that although patients' sensory and affect intensity ratings were available, the construction of tapes for this study was based on the affect ratings. Similarly, in the judgment studies, observers made ratings using the affect scales. This was because previous research had shown that the affect scales yield slightly higher patient-observer correlations than the sensory scales. The facial actions of the subjects had been measured with an abbreviated version of the Facial Action Coding System (14). Consequently, it was possible to construct and evaluate the videotapes, knowing both the subjects' self-reports of pain intensity on each trial and the strength of one type of pain signal available in their behaviour.

The selection of excerpts to be included in the final videotape was based on prior analyses that had been performed on the subjects' self-reports and facial expression. Factor analyses of the structure of the verbal report and facial expression measures have shown that each contains two overall dimensions: one that reflects the intensity of pain experienced or displayed on active tests (in which the subject has control over the movement) and one that reflects the intensity of pain experienced or displayed on passive tests (in which the movement is controlled by the therapist). The same tests correlate with active and passive dimensions on verbal and facial action measures (6). The excerpts selected for presentation met three criteria. First, the full range of tests reliably contributing to the aforementioned active and passive factors was selected. Thus, observers viewed each selected patient's reactions to four active and five passive tests. Second, individual patients were selected for display on the videotapes if their verbal report was consistent with their facial expressions. To do this, the patients' self-report and facial expression factor scores were examined and those subjects whose response styles were not consistent (ie, those who showed much facial pain but stated that they were in little pain and vice versa) were eliminated. This process resulted in the selection of 20 individuals (four males, six females), four of whom could be deemed 'expressive' (ie, their self-report and facial expression both indicated high levels of pain) and six could be deemed 'unexpressive' (self-report and facial expression indicated little pain). This satisfied the third criterion of sampling a range of expressiveness. The videotaped excerpts selected for study were edited onto a test tape, on which patients were randomly assigned. The final stimulus tape contained 88 excerpts averaging $12 \mathrm{~s}$ in length. Each was preceded and followed by an interval of $5 \mathrm{~s}$ of blank tape.

Videotapes were displayed to observers on 21-inch television screens. They sat at a self-selected distance from the screen and participated in groups with a maximum size of seven persons and an average size of three persons. All observers viewed the excerpts in the same order. Each observer was presented with a folder containing a form for making their ratings of the subject and a $15 \times 10 \mathrm{~cm}$ cue card that listed the verbal pain affect descriptors they were to use to characterize the patients' pain. The descriptors were the same as those used by the patients. The letters A through $\mathrm{P}$ were presented beside each descriptor.

\section{Procedure}

Observers were told that the study examined how people interpret pain in others. The nature of the excerpts that they would be watching and the tests that would be involved 


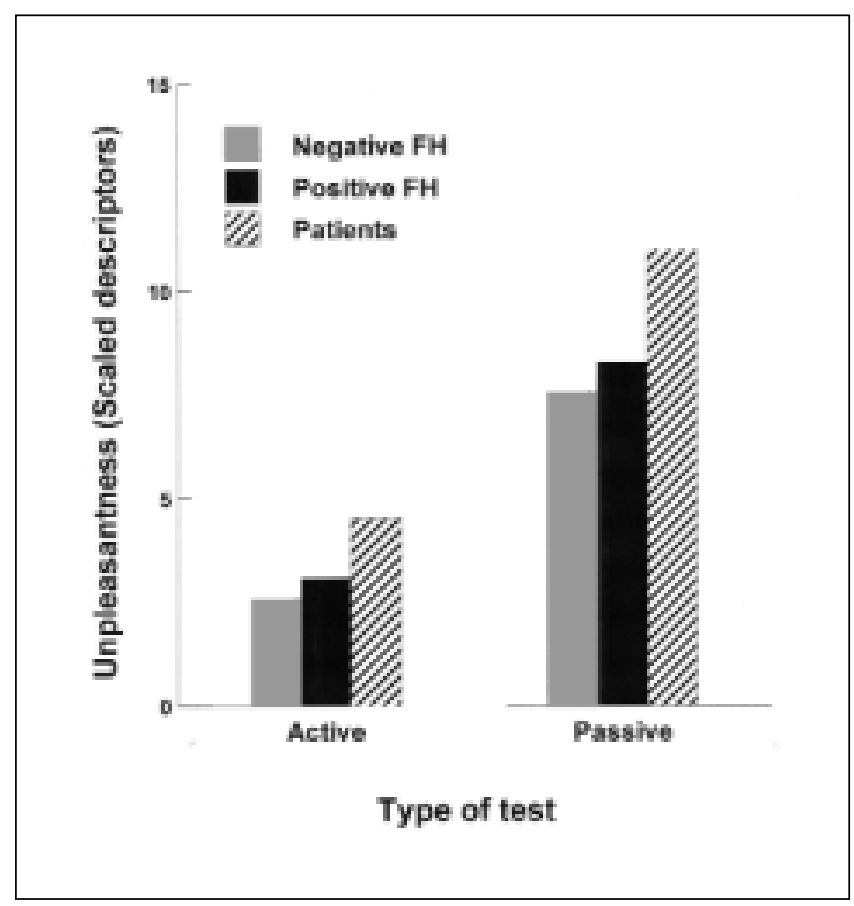

Figure 1) Ratings of pain on active and passive tests by groups with negative and positive family histories $(\mathrm{FH})$ of chronic pain. Patients' average ratings of the same pain are presented for comparison

were then explained. Observers were told to observe each excerpt and make a judgment about how much pain the person must have experienced based on what they saw in the excerpt. They were told to view the entire excerpt and then use the intertrial interval to make their rating by recording the letter associated with the appropriate descriptor on the response form. Once the experimenter was sure that the observers understood their task, she began the videotape.

\section{Results}

Each observer's average rating of the pain expressed on active and passive tests was calculated separately for expressive and inexpressive patients. These averages were then entered in a two (positive versus negative family history of pain) by two (sex of observer) by two (high versus low expressiveness of subject) by two (active versus passive test) ANOVA. Although the latter two factors were not of primary interest, the videotapes were constructed with these manipulations built into them. It was plausible to expect expressiveness, the nature of the test and sex to account for significant proportions of variance in observers' pain judgments. Therefore, these factors were included in the ANOVA to improve the power of the analysis and to investigate possible interactions with the main variable of interest, family history. There was a trend toward significance for the family history effect $(\mathrm{F}[1,78]=3.08, \mathrm{P}=0.08)$ and a significant family history and active/passive test interaction $(\mathrm{F}[1,78]=6.24, \mathrm{P}<0.05$, $\eta^{2}=0.08$ ). The means are presented in Figure 1. On passive tests, observers having a positive family history of chronic pain imputed greater pain to patients than did observers with no family history of chronic pain.
TABLE 1

Average Pearson correlations between observers' and patients' pain ratings for expressive and unexpressive patients on active and passive tests

\begin{tabular}{lllll}
\hline & \multicolumn{2}{c}{ Active test } & \multicolumn{1}{c}{ Passive text } \\
& $\begin{array}{c}\text { Unexpressive } \\
\text { patient (SD) }\end{array}$ & pxpressive & Unexpressive & Expressive \\
patient (SD) & patient (SD) \\
\hline $\begin{array}{c}\text { Negative family } \\
\text { history of pain }\end{array}$ & $0.28(0.22)$ & $0.12(0.14)$ & $0.62(0.13)$ & $0.37(0.20)$ \\
$\begin{array}{c}\text { Positive family } \\
\text { history of pain }\end{array}$ & $0.29(0.19)$ & $0.13(0.12)$ & $0.62(0.15)$ & $0.36(0.22)$ \\
$\begin{array}{c}\text { Health care } \\
\text { professional }\end{array}$ & $0.27(0.21)$ & $0.13(0.11)$ & $0.65(0.15)$ & $0.31(0.20)$ \\
\hline
\end{tabular}

The Pearson correlation between each observer's rating of pain and the subjects' ratings was calculated. Examination of the distributions of these correlations indicated that they did not depart substantially from normality (skewness values ranged from -0.28 to -0.64$)$. Consequently, they were entered as dependent variables in an ANOVA of the same form. The results of this analysis revealed no main effects or interactions involving the family history variable. A significant active/passive and expressiveness interaction $(\mathrm{F}[1,80]=345.84, \mathrm{P}<.001)$ was observed. The descriptive statistics associated with this effect are presented in Table 1. In interpreting this interaction, it is important to point out that only for judgments of inexpressive patients undergoing passive tests did the $95 \% \mathrm{CI}$ around the mean not include 0 . Thus, only in the inexpressive patient/active test condition is it possible to conclude that observers, on average, were sensitive to variations in patients' self-reports of pain by observing their facial behaviour.

\section{Discussion}

The results indicate that experience living with someone who suffers from chronic pain is associated with differences in interpreting information about pain in others. Observers with a positive family history of pain tended to give higher ratings of the pain displays of strangers than did observers without such a history. This difference was most pronounced and statistically significant when the observers viewed pain expressions made during passive movements of patients' arms. Previous results have shown that passive movements were associated with much greater degrees of pain expression than active movements (7). Thus, the differences in the perception of others' pain were most apparent when the judges had the greatest amount of pain expression to observe.

This study took advantage of the existence of intact groups of observers with differing family histories of pain and is therefore only correlational. The possibility that something about the tendency to impute greater pain to others enhances the likelihood of there being a pain patient in one's family cannot be ruled out, however unlikely it 
seems. It appears reasonable to suggest, however, that experience living with a family member having chronic pain may exert a causal impact on observers' pain judgments. The potential extent of this impact is impossible to establish on the basis of this study, because we did not collect information on the nature of the relationships that our observers had with their family members. Although observers with a positive family history of pain all met the same criteria, it is likely that some of them would have had quite minimal experience. On the other hand, some could have had extensive experience with the sufferer, perhaps playing the role of primary caregiver. Consequently, the generalizability of the findings is unknown, although it would appear that they represent the minimal impact of experience. Future studies may evaluate profitably the impact of varying degrees of experience or roles.

Despite that observers were more likely to impute pain to others when they had experience living with someone having chronic pain, they were no more or less sensitive to variations in the patients' pain than observers with no family history of pain, as indicated by the lack of differences between family history groups in the correlations between observers' and patients' ratings. This supports the suggestion that a distinction can be made between the weight that observers' place on the evidence of pain in others and their sensitivity to variations in sufferers' pain experience. It remains to be determined whether other experiential variables may affect the sensitivity dimension differentially.

\section{STUDY 2}

The second study was an extension of the first. The authors were interested in whether a different kind of experience with pain sufferers would relate to observers' pain judgments. Many people have a stake in being able to draw conclusions about the pain of others. Perhaps foremost among these are professionals whose daily experience involves dealing with pain sufferers - clinicians such as physicians, nurses and rehabilitation workers.

Studies of the perception of others' pain among professional groups have been performed, primarily with nurses. There has been some consistency in the finding that they tend to give lower pain ratings than the sufferers themselves. For example, Teske et al (15) compared the visual analogue scale (VAS) ratings nurses gave of the pain of acute and chronic patients with the ratings of the patients themselves. The nurses' ratings, especially of the chronic patients, were lower. The tendency for nurses to give systematically lower ratings of pain than patients themselves has also been reported by Stephenson (16), who examined the postoperative pain of abdominal, orthopedic and gynecological patients; Zalon (17), who also worked with abdominal surgery patients; Hall-Lord et al (18), who worked with elderly intensive care unit patients; and Thomas et al (19), who worked with orthopedic surgery patients. In a study that also looked at other professional groups, Grossman et al (20) compared the VAS ratings of nurses, house officers and oncology fellows with cancer patients. When percentage agreement between caregiver and patient was examined, there was a clear trend for the agreement to decrease as the patient's pain level increased (ie, the greater the patient's pain, the more the health professional tended to underestimate it).

On the other hand, some studies have obtained less robust evidence of underestimation among health professionals. Choiniere et al (21) compared nurses' VAS ratings with those of burn pain patients and concluded that $43 \%$ of the nurses underestimated, but $27 \%$ overestimated, patients' pain. Nurses with greater experience were more likely to underestimate pain, while those with less experience were more likely to overestimate pain. Iafrati (22) compared nurses' VAS ratings with those of burn patients and concluded that nurses' estimates were correct $31 \%$ of the time, while $34.5 \%$ overestimated and $34.5 \%$ underestimated pain. There was a trend for more experienced nurses to underestimate pain. Olden et al (23) found that nurses were as likely to underestimate as overestimate pain after Cesarean section.

Thus, there is a general indication that nurses, and perhaps other professional groups, underestimate pain, relative to sufferers; however, there is also inconsistency in this finding. Interestingly, in studies reporting equivocal underestimation effects, there is also evidence that increasing amounts of experience are associated with increased underestimation, a finding also reported by VonBaeyer et al (24) among nurses in training.

Taken together, existing findings lead to the counterintuitive expectation that clinical experience with pain patients would be associated with lower pain ratings. Nevertheless, the research to date has examined a relatively limited number of professional groups. Among the groups of professionals who have the most experience with pain sufferers are physiotherapists and occupational therapists, who spend considerable time assessing both the pain and functional status of pain patients, and who perform a variety of therapeutic manoeuvres designed to enhance patients' functioning and reduce their pain. Understanding of the generality of underestimation of pain among professional groups would be enhanced by examination of this group.

Moreover, although the research to date has focused on pain evaluation in the clinical setting, the studies have provided virtually no control over the phenomena the professional groups have used to base their judgments on. The present study provided greater control over the stimulus display contributing to the clinician-observer's judgments by presenting facial displays in which the facial behaviour and subjective ratings were known precisely.

\section{Subjects and methods}

Subjects were 34 licensed physical and occupational therapists practising at a major Canadian medical centre. The average age of the therapists was 32 years $(\mathrm{SD}=7.5)$. On average, they had been practising for eight years $(\mathrm{SD}=7.4)$. Subjects observed and rated the same videotape used in the previous study under identical instructions and conditions. 


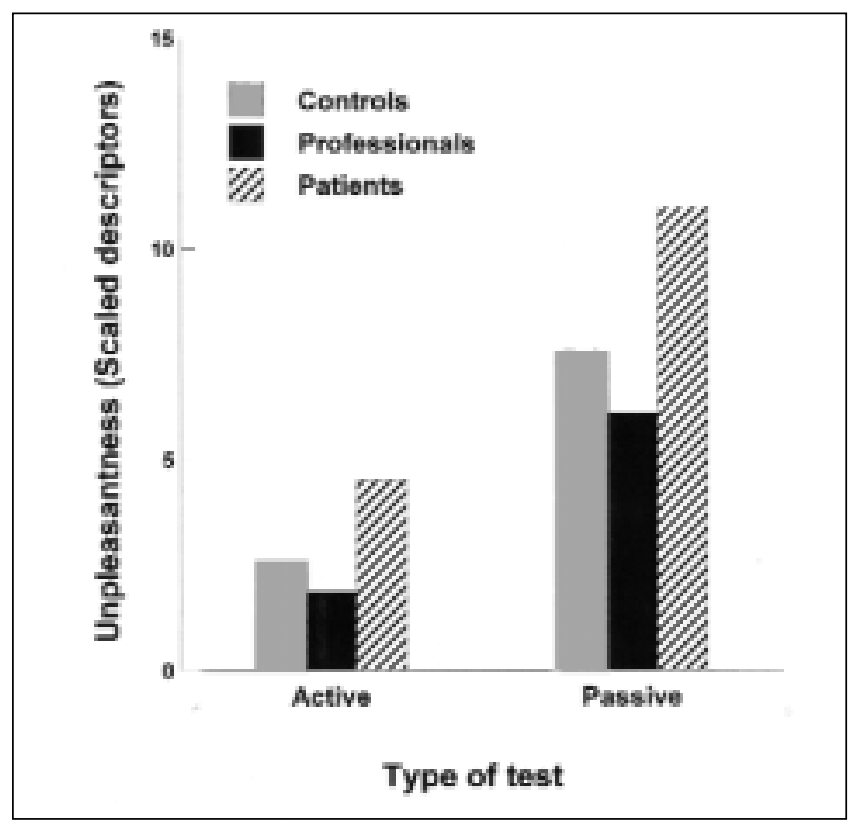

Figure 2) Ratings of pain on active and passive tests by observers having no experience with chronic pain and pain professionals. Patients' average ratings of the same pain are presented for comparison

\section{Results}

Data from the professionals were compared with those obtained for subjects without a family history of pain in the previous study. The average rating of expressive and unexpressive patients' pain was calculated for each subject and entered into a two (groups: professionals versus controls) by two (expressiveness of patient) by two (active versus passive test) ANOVA. The results revealed a significant effect attributable to experience. Relative to controls, professional subjects provided reliably lower estimates of patients' pain in all circumstances $\left(\mathrm{F}[1,88]=6.63, \mathrm{P}=0.01, \eta^{2}=0.08\right)$. Means are presented in Figure 2.

The comparable analysis of differences in the correlation between patients' and subjects' pain ratings revealed the same pattern as study 1 , with a significant interaction between active/passive and expressiveness $(\mathrm{F}[1,88]=16.15, \mathrm{P}<0.01)$ but no reliable effects attributable to category of observer.

\section{Discussion}

The collective findings are consistent with the suggestion that different kinds of life experiences involving people who suffer pain are related to perception of pain behaviour. In study 1 , the ratings of observers who reported having lived with a chronic pain sufferer were higher and closer to those of the patients that they observed than those who reported no such experience; however, this was only true for tests in which the patients actually displayed high levels of pain. In study 2 , health care professionals, specifically physical and occupational therapists, who work with people with pain problems, gave ratings that were significantly lower than the ratings of nonprofessionals and diverged to a greater degree from the ratings of the patients themselves. In this case, the professionals' ratings were lower than the nonprofessionals' across all categories of test. In the first study, evidence for an influence of experience was a family history and 'type of test' interaction. In the second, it was a main effect for observer group. In both cases, the effect size estimates were almost identical at $\eta^{2}=0.08$. In both studies, the influence of the background variables (family history of pain problems, experience as a pain professional) was restricted to the general rating of patients' pain (ie, the 'weight' that they placed on pain expression). They had no association with the correlation between the subjects' and the patients' ratings (ie, on sensitivity to variations in the patients' internal states).

Because these findings were obtained with intact groups in which variations in experience were taken advantage of rather than manipulated, it is impossible to be certain that the differing experiences of the groups are responsible for the differences found in their perception of sufferers' pain. Nevertheless, the findings do identify experiential effects as a plausible potential explanation. If experience does have a causal impact on the perceptions of others' pain, the present findings imply that this impact is not unidirectional. In study 1 , experience was associated with a tendency to rate the pain of others higher; in study 2, it was associated with a tendency to rate the pain of others lower. Clearly, however, the experience of living with someone who has chronic pain is different from the experience of dealing in a professional capacity with people who suffer from pain. To clarify the nature of experiential effects on pain judgment, a better understanding of how the dimensions of the experiences of different groups of judges vary will be necessary.

There is little theory or evidence to illuminate these issues. However, a consideration of differences in the living circumstances, role responsibilities and background of family members and professionals may give some clues. The family has been considered a crucible within which interpersonal forces may affect pain expression $(1,8)$. One of the interpersonal influences at play within families is the communication of internal states: emotions, attitudes, aspirations and, of course, suffering. It seems reasonable to suggest that people who have had a family member who has experienced chronic pain would also have had more opportunity to associate pain expression with evidence that would help them calibrate their judgments of others' suffering than people without this experience. It may also be expected that an observer's perceptions of others' suffering would depend on characteristics of their family. There has been speculation that aspects of the family environment - closeness, communication styles and decision-making characteristics, for example - may be responsible for variations in pain expression on the part of sufferers. Such variables may also affect the perception of pain expression on the part of the family members. Though plausible, these suggestions go well beyond the present findings.

It may be possible to draw more definite generalizations from the findings of study 2 , in which physical and occupational therapists showed an exaggeration of the previously 
reported tendency for observers in general to underestimate others' pain (6). This finding is consistent with the evidence on the pain judgments of other groups, suggesting that it reflects a fairly general characteristic of health care professionals. Health care professionals who deal with pain would seem to have a stake in being able to gauge the suffering of others well. In addition, given the levels of exposure that they are likely to have had with suffering, they may be expected to have developed better ways of titrating others' pain. From this point of view, the present findings and the existing literature are surprising and potentially alarming. It may be argued that the ability to predict the absolute level of a sufferer's pain is less important to the professional than sensitivity to variations in the pain state. If so, the findings still are not comforting, because the professionals were no better than controls at detecting variation in pain state. Hence, the present findings are consistent with those from other studies of sensitivity to nonverbal communication, indicating that several groups of people who ought to have a professional or avocational interest in making effective use of nonverbal cues are not especially good at it (25).

Why might health care professionals have this tendency to rate evidence of pain lower than people who have little or no experience with pain sufferers? One possibility is the 'distancing' that health care workers are said to experience as a result of adapting to clinical practice. It is often suggested that health care workers must learn how to filter the evidence of suffering to which they are exposed on a daily basis to carry on in their jobs. Conceivably, such a process could translate into a tendency to ignore or downgrade evidence of pain in others. On the other hand, it may be that the tendency to downgrade evidence of pain in others may be a direct consequence of the way that clinicians are taught to think about and deal with pain. Clinicians often learn, either directly or indirectly, that the phenomena of pain are of secondary interest; what is truly important, from a clinical perspective, is to get to the root of the problem by establishing the nature and source of the lesion that is its substrate or by correcting underlying dysfunction. By encouraging clinicians to focus on diagnosing and remedying the underlying cause of pain, clinical training may simultaneously lead them to be inattentive to the behavioural phenomena that communicate the experience.

Other explanations for the lower pain ratings of professionals also exist. One is that the findings for professionals reflect a contrast phenomenon. Perhaps clinicians use their memory of extreme clinical experiences in which patients have shown intense suffering as a calibration standard. In relation to such memories, the examples of pain expression in the present study may have been pale by comparison, leading to a downrating of the pain. It is also possible that the present findings simply reflect clinicians' reliance on cues other than nonverbal behaviour. Finally, the differences between professionals and nonprofessionals may reflect differences in general life experience, given that the professionals in study 2 were considerably older than the nonprofessionals.
These interpretations warrant investigation in future research. Moreover, given some of the counterintuitive findings of the present study and the fact that they were obtained by comparing data from clinicians with already available information from controls, they should be replicated. Considering the clear statistical differences obtained, however, and the potentially profound implications of the findings, further examination of these apparent differences and their sources are warranted.

Several limitations to the present findings should be emphasized. First, the patients whose facial behaviour was shown to judges all suffered from a particular type of pain shoulder pain. It is possible that judgments of patients who suffer from different types of pain may not show the same effects observed in this study. Second, although the videotape that the participants watched displayed patients and tests in a random order, all judges viewed the tape in the same sequence. Therefore, we were unable to evaluate any order effects that may have occurred. Third, the broader clinical significance of the differences observed is unclear. The practical impact can only be established in studies in which other health outcomes (eg, disability, quality of life) are examined. Fourth, the meaning of the lack of betweengroup differences in the correlation between patients' and observers' ratings is ambiguous. A posthoc analysis of statistical power (26) indicated that, for both studies, the sample sizes were only sufficient to detect a large statistical effect with a probability of greater than 0.80 . Thus, experiential differences associated with effects of small or moderate size were unlikely to be detected. Finally, in both studies, there were substantially more female than male subjects, placing constraints on the generalizability of the findings. However, because research has generally shown that females outperform males on measures of sensitivity to nonverbal cues (27), it is possible that the findings actually underestimate the phenomenon in the population at large.

\section{CONCLUSIONS}

The present findings confirm earlier observations (6) that, relative to the sufferers themselves, observers tend to underestimate the pain of others when making inferences based on facial behaviour. Moreover, they provide evidence that experience, in the form of exposure to people suffering from pain, is associated with systematic differences in the way that observers make judgments of the pain of others. Experience living with a pain sufferer appears to be associated with a reduction in the ordinary underestimation bias in some circumstances, whereas clinical experience with pain patients appears to be associated with an exaggeration of that bias.

\section{REFERENCES}

1. Fordyce WE. Behavioural Methods for Chronic Pain and Illness. St Louis: CV Mosby, 1976.

2. Rosenthal R. Conducting judgement studies. In: Scherer K, Ekman P, eds. Handbook of Methods in Nonverbal Behavior Research. New York: Cambridge University Press, 1982.

3. Craig KD, Prkachin KM, Grunau RVE. The facial expression of pain. In: DC Turk, R Melzack, eds. Handbook of Pain Assessment, 2nd edn. New York: Guilford. (In press) 
4. LeResche L, Dworkin SF. Facial expressions of pain and emotions in chronic TMD patients. Pain 1988;35:71-8.

5. Prkachin KM. The consistency of facial expressions of pain: A comparison across modalities. Pain 1992;51:297-306.

6. Prkachin KM, Berzins SA, Mercer SR. Encoding and decoding of pain expressions: A judgement study. Pain 1994;58:253-9.

7. Prkachin KM, Mercer SR. Pain expression in patients with shoulder pathology: validity, properties and relationship to sickness impact. Pain 1989;39:257-65.

8. Turk DC, Flor H, Rudy TE. Pain and families. I. Etiology, maintenance and psychosocial impact. Pain 1987;30:3-27.

9. Flor H, Turk DC, Rudy TE. Pain and families. II. Assessment and treatment. Pain 1987;30:29-45.

10. Meissner WW. Family process and psychosomatic disease. Int J Psychiatry Med 1974;5:411-30.

11. Minuchin S, Rosman B, Saker L. Psychosomatic Families. Cambridge: Harvard University Press, 1978.

12. Prkachin GC, Prkachin KM. Adaptation to facial expressions of emotion. Cognit Emotion 1994;8:55-64.

13. Heft MW, Gracely RH, Dubner R, McGrath PA. A validation model for verbal descriptor scaling of human clinical pain. Pain 1980;9:363-73.

14. Ekman P, Friesen WV. The Facial Action Coding System. Palo Alto: Consulting Psychologists' Press, 1978.

15. Teske K, Daut R, Cleeland C. Relationships between nurses' observations and patients' self-reports of pain. Pain 1983;16:289-96.

16. Stephenson N. A comparison of nurse and patient: Perceptions of postsurgical pain. J Intraven Nurs 1994;17:235-9.
17. Zalon M. Nurses' assessment of postoperative patients' pain. Pain 1993;54:329-34.

18. Hall-Lord M, Larsson G, Steen B. Pain and distress among elderly intensive care unit patients: comparison of patients' experiences and nurses' assessments. Heart Lung 1998;27:123-32.

19. Thomas T, Robinson C, Champion D, McKell M, Pell M. Prediction and assessment of the severity of post-operative pain and of satisfaction with management. Pain 1998;75:177-85.

20. Grossman S, Sheidler V, Swedeen K, Mucenski J, Piantadosi S. Correlation of patient and caregiver ratings of cancer pain. J Pain Symptom Manage 1991;6:53-7.

21. Choiniere M, Melzack R, Girard N, Rondeau J, Paquin MI. Comparisons between patients' and nurses, assessment of pain and medication efficacy in severe burn injuries. Pain 1983;20:143-52.

22. Iafrati N. Pain on the burn unit: patient versus nurse perceptions. J Burn Care Rehabil 1986;7:413-6.

23. Olden A, Jordan E, Sakima N, Grass J. Patients' versus nurses' assessments of pain and sedation after cesarean section. J Obstet Gynecol Neonatal Nurs 1995;24:137-41.

24. VonBaeyer C, Johnson M, McMillan M. Consequences of nonverbal expression of pain: Patient distress and observer concern. Soc Sci Med 1984;19:1319-24.

25. Ekman P, O'Sullivan M. Who can catch a liar? Am Psychol 1991;9:913-20.

26. Cohen J. Statistical Power Analysis for the Behavioural Sciences, 2nd edn. Hillsdale: Erlbaum, 1988.

27. Hall JA. Gender effects in decoding nonverbal cues. Psychol Bull 1978;85:845-57. 


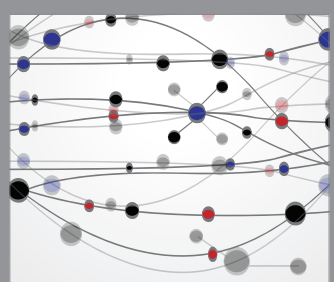

The Scientific World Journal
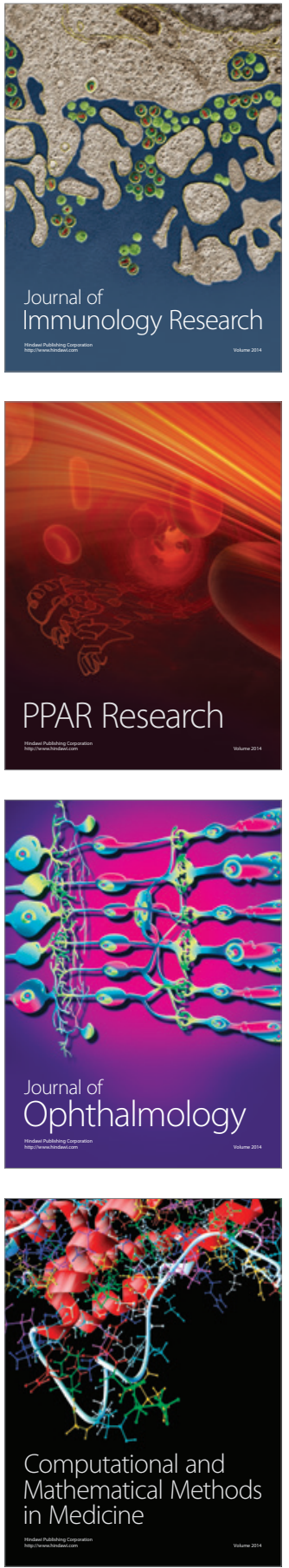

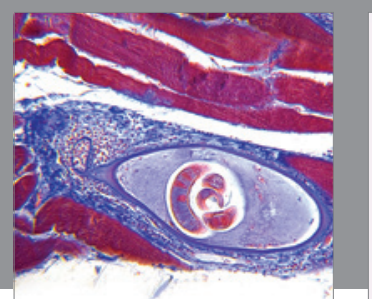

Gastroenterology Research and Practice

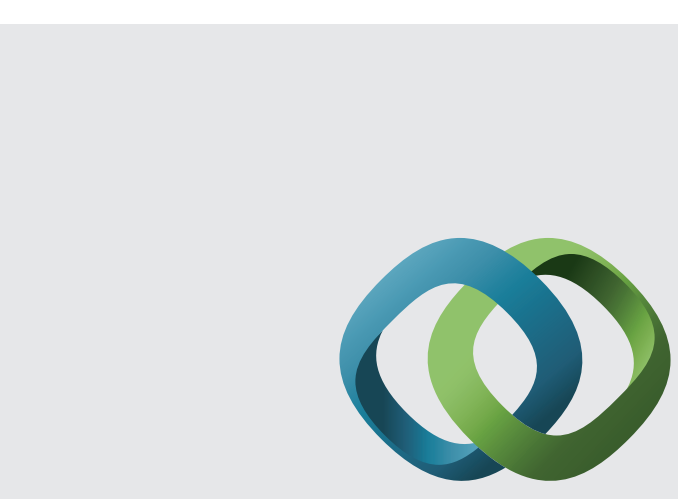

\section{Hindawi}

Submit your manuscripts at

http://www.hindawi.com
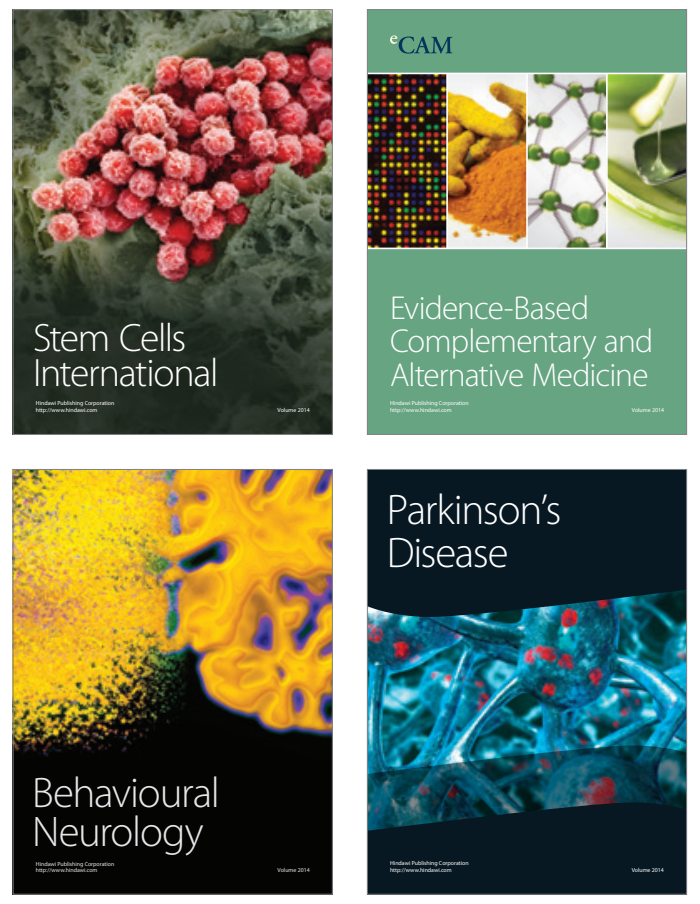
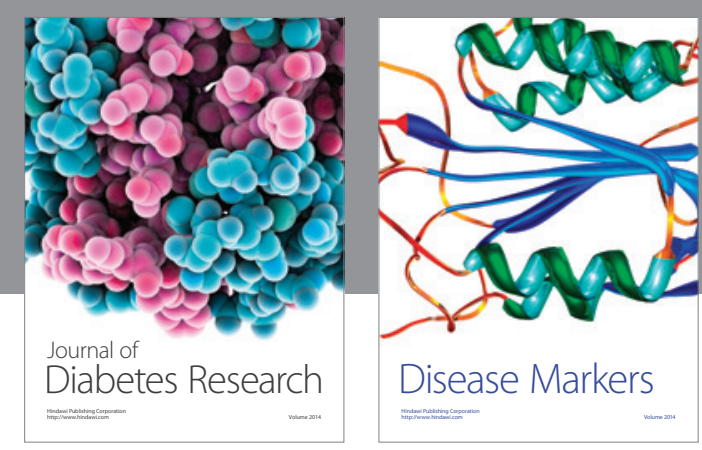

Disease Markers
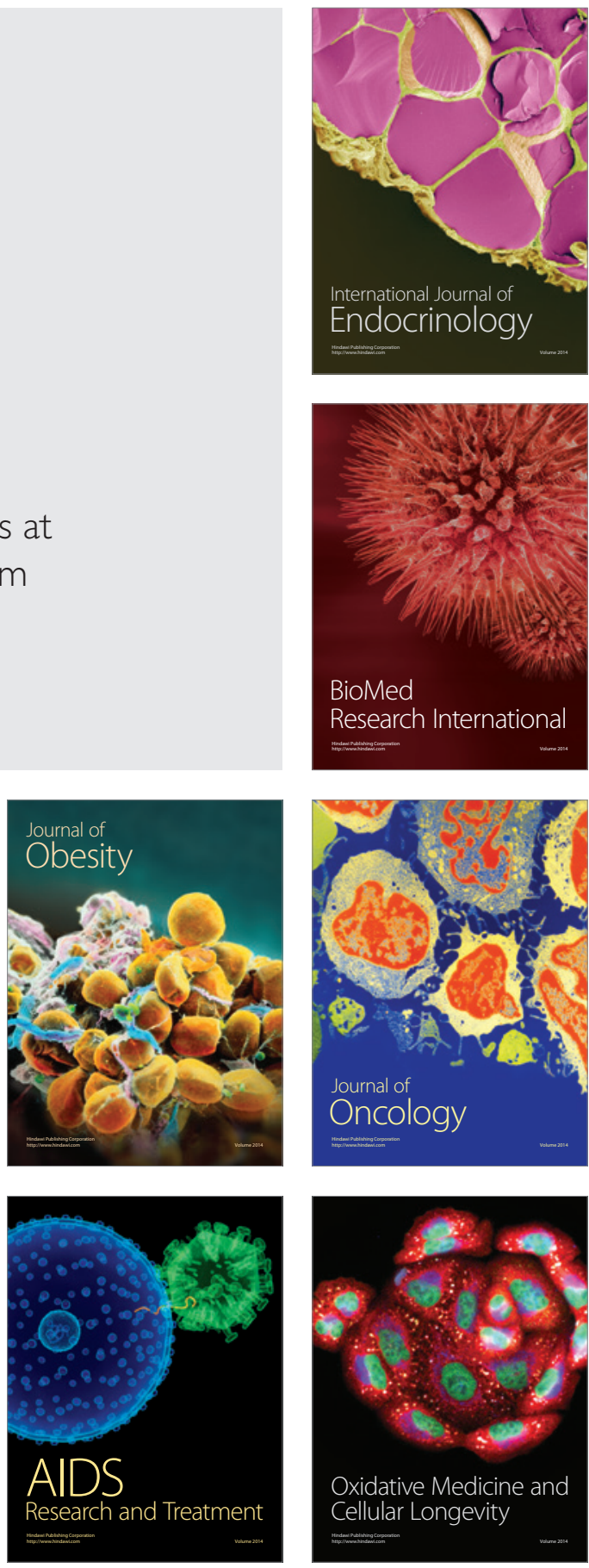